\title{
SUBGRUP FUZZY ATAS SUATU GRUP
}

\author{
Fatkhur Rozi, Ari Wardayani, dan Suroto \\ Program Studi Matematika Fakultas Sains dan Teknik \\ Universitas Jenderal Soedirman \\ email : cahcilacap07@yahoo.com
}

\begin{abstract}
This paper discusses a fuzzy subgroup of a classical group. It's constructed by defining fuzzy subsets and employing products and inverse notions on classical group. The result obtained is sufficient and necessary conditions for the fuzzy subset to be fuzzy subgroup.
\end{abstract}

Keywords: group, fuzzy subset, fuzzy subgroup

ABSTRAK. Makalah ini membahas tentang subgrup fuzzy atas suatu grup klasik. Pembentukan subgrup fuzzy dilakukan melalui subhimpunan fuzzy dengan memanfaatkan nilai dari hasil kali dua buah elemen serta invers elemen pada grup klasiknya. Hasil yang diperoleh adalah syarat cukup dan perlu suatu subhimpunan fuzzy merupakan subgrup fuzzy.

Kata kunci: grup, subhimpunan fuzzy, subgrup fuzzy

\section{PENDAhuluaN}

Operasi biner pada suatu himpunan tak kosong S merupakan suatu fungsi dari SxS ke S (Judson, 2011). Grup merupakan suatu sistem matematika yang terdiri atas sebuah himpunan tak kosong dan dilengkapi dengan sebuah operasi biner yang memenuhi sifat assosiatif, memiliki elemen identitas, dan setiap elemennya memiliki invers (Fraeligh, 2000). Selanjutnya suatu grup yang operasi binernya bersifat komutatif dinamakan grup komutatif (abel). Kajian mengenai teori grup klasik kebanyakan dilakukan pada himpunan tegas (crisp).

Kajian mengenai konsep himpunan mulai berkembang pada sekitar tahun 1965 yang ditandai dengan adanya perluasan dari konsep himpunan tegas menjadi himpunan fuzzy (samar). Menurut Malik dan Mordeson (2002), himpunan fuzzy atas suatu himpunan $X$ merupakan suatu fungsi dari $X$ ke interval tutup [0,1] dan merupakan generalisasi dari himpunan tegas. Dengan kata lain, himpunan tegas merupakan kasus khusus dari himpunan fuzzy, sehingga sifat yang ada pada 
himpunan tegas pasti dapat dinyatakan sebagai kasus khusus dari sifat himpunan fuzzy.

Pembahasan mengenai teori dan aplikasi dari himpunan fuzzy banyak dilakukan pada tahun-tahun berikutnya. Beberapa aplikasi konsep himpunan fuzzy pada kehidupan nyata telah di bahas oleh Lee (2005). Pembahasan mengenai pembentukan subhimpunan fuzzy pada suatu grup klasik telah dibahas oleh Mordeson dkk (2005). Selanjutnya, penelitian mengenai penggunaan konsep himpunan fuzzy pada pembentukan ruang vektor dan matriks juga telah di bahas oleh Mufidah (2011). Pada tulisan ini dibahas mengenai pembentukan subgrup fuzzy dari suatu grup klasik dan beberapa sifat yang terkait, serta contoh kasusnya. Pada pendefinisian subgrup fuzzy ini akan memanfaatkan konsep subhimpunan fuzzy dari suatu grup klasik. Selanjutnya dengan membentuk subgrup fuzzy ini maka suatu grup klasik akan dapat dinyatakan sebagai kasus khusus dari suatu subgrup fuzzy. Pada bagian utama tulisan ini, pertama akan dibahas mengenai pembentukan subgrup fuzzy atas suatu grup klasik. Kedua, akan dibahas mengenai sifat terkait subgrup fuzzy yakni syarat cukup dan perlu dari suatu subhimpunan fuzzy merupakan subgrup fuzzy yang merupakan hasil utama pada tulisan ini.

\section{METODE PENELITIAN}

Penelitian ini merupakan suatu penelitian yang didasarkan pada studi literatur yang meliputi kajian-kajian secara teoritis. Langkah awal yang dilakukan adalah mendefinisikan sembarang grup klasik dan membentuk subhimpunan fuzzy pada grup klasik tersebut. Dari subhimpunan fuzzy ini, selanjutnya dapat dibentuk suatu subgrup fuzzy atas suatu grup klasik dan beberapa contoh kasusnya. Langkah berikutnya adalah membuktikan beberapa sifat terkait syarat cukup dan perlu dari suatu subhimpunan fuzzy merupakan subgrup fuzzy dan contoh kasusnya. 


\section{HASIL DAN PEMBAHASAN}

Bagian ini merupakan bagian utama dari tulisan ini yang berisi tentang pembentukan subgrup fuzzy dan sifat terkait subgrup fuzzy.

\subsection{Pembentukan Subgrup Fuzzy}

Untuk membentuk suatu subgrup fuzzy maka terlebih dahulu didefinisikan subhimpunan fuzzy atas suatu grup klasik. Apabila $G$ adalah suatu grup (klasik), maka untuk mendefinisikan subhimpunan fuzzy atas grup $G$ sama halnya dengan mendefinisikan suatu subhimpunan fuzzy atas sembarang himpunan $X$.

\section{Definisi 1}

Misalkan $G$ adalah suatu grup. Subhimpunan fuzzy atas grup $G$ adalah fungsi $\mu: G \rightarrow$ [0,1] yang mengaitkan setiap elemen di $G$ ke interval tutup [0,1]. Selanjutnya, himpunan dari semua subhimpunan fuzzy atas $G$ dinamakan himpunan kuasa fuzzy atas grup $G$ dan dinotasikan dengan $F P(G)$ dan $\mu(x)$ untuk setiap $x \in G$ dinamakan nilai keanggotaan elemen $x$ pada subhimpunan fuzzy $\mu$.

Berikut merupakan contoh mengenai subhimpunan fuzzy atas suatu grup.

\section{Contoh 1}

Diketahui bahwa $\mathbb{Z}_{5}-\{\overline{0}\}$ merupakan grup dengan operasi $\times_{5}$. Order elemen $x$ pada suatu grup merupakan bilangan bulat positif terkecil $n$ sedemikian hingga $x^{n}=1$ dan ditulis $d(x)=n$. Didefinisikan fungsi $\mu: \mathbb{Z}_{5}-\{\overline{0}\} \rightarrow[0,1]$ dengan $\mu(x)=\frac{1}{\operatorname{ord}(x)}$ untuk setiap $x \in \mathbb{Z}_{5}-\{\overline{0}\}$. Perhatikan bahwa $\operatorname{ord}(\overline{1})=1, \operatorname{ord}(\overline{2})=4, \operatorname{ord}(\overline{3})=4$, dan $\operatorname{ord}(\overline{4})=2$, sehingga diperoleh $\mu(\overline{1})=1, \mu(\overline{2})=0,25, \mu(\overline{3})=0,25$, dan $\mu(\overline{4})=0,5$. Dengan demikian $\mu$ adalah suatu fungsi dimana $\mu(x) \in[0,1]$ untuk setiap $x \in \mathbb{Z}_{5}-\{\overline{0}\}$, sehingga $\mu$ merupakan subhimpunan fuzzy atas grup $\mathbb{Z}_{5}-\{\overline{0}\}$ dan $\mu \in F P\left(\mathbb{Z}_{5}-\{\overline{0}\}\right)$.

\section{Contoh 2}

Diketahui $H=\{1,-1, i,-i\}$ yang dilengkapi operasi $\times$ merupakan suatu grup. Didefinisikan fungsi $\sigma$ dengan 


$$
\sigma(x)=\left\{\begin{array}{l}
\cos \left(\frac{\operatorname{Arg}(x)}{2}\right), \text { untuk } x=1, i,-i \\
\sin \left(\frac{\operatorname{Arg}(x)}{3}\right), \text { untuk } x=-1
\end{array}\right.
$$

dan $\operatorname{Arg}(x)$ adalah argumen utama dari $x$. Perhatikan bahwa $\operatorname{Arg}(1)=0, \operatorname{Arg}(-1)=$ $\pi, \operatorname{Arg}(i)=\frac{\pi}{2}, \operatorname{dan} \operatorname{Arg}(-i)=-\frac{\pi}{2}$, sehingga hasil dari $\sigma(1)=1, \sigma(-1)=\frac{\sqrt{3}}{2}$,

$\sigma(i)=\frac{\sqrt{2}}{2}$, dan $\sigma(-i)=\frac{\sqrt{2}}{2}$. Dengan demikian $\sigma$ adalah suatu fungsi dimana $\sigma(x) \in$ $[0,1]$ untuk setiap $x \in H$. Dengan kata lain $\sigma$ merupakan subhimpunan fuzzy atas grup $H$ dan $\sigma \in F P(H)$.

Selanjutnya didefinisikan operasi biner dan uner pada himpunan kuasa fuzzy atas grup $G$ yang akan digunakan untuk membuktikan beberapa sifat yang berlaku pada subgrup fuzzy atas grup $G$. Definisi dari operasi biner dan uner pada himpunan kuasa fuzzy atas grup $G$ dijelaskan pada definisi berikut.

\section{Definisi 2}

Misalkan $G$ adalah suatu grup. Operasi biner odan uner $\quad{ }^{-1}$ pada $F P(G)$ berturutturut didefinisikan dengan

$$
(\mu \circ v)(x)=\sup \{\min \{\mu(y), v(z)\} \mid y z=x \text {, untuk } y, z \in G\} \text { dan } \mu^{-1}(x)=\mu\left(x^{-1}\right)
$$

untuk setiap $\mu, v \in F P(G)$ dan $x \in G$.

Selanjutnya $\mu \circ v$ dinamakan hasil kali dari $\mu$ dan, serta $\mu^{-1}$ dinamakan invers dari $\mu$.

Subgrup fuzzy atas grup $G$ merupakan subhimpunan fuzzy atas grup $G$ yang memenuhi syarat-syarat tertentu. Berikut diberikan definisi dari subgrup fuzzy atas grup $G$. 


\section{Definisi 3}

Misalkan $G$ adalah grup dan $\mu \in F P(G)$ maka $\mu$ dikatakan subgrup fuzzy atas $G$ jika memenuhi $\mu(x y) \geq \min \{\mu(x), \mu(y)\}$ dan $\mu\left(x^{-1}\right) \geq \mu(x)$ untuk setiap $x, y \in G$

Untuk selanjutnya, himpunan dari semua subgrup fuzzy atas grup $G$ dinotasikan $F(G)$

Contoh berikut merupakan penjelasan dari subgrup fuzzy atas suatu grup.

\section{Contoh 3}

Diketahui bahwa $\mu: \mathbb{Z}_{5}-\{\overline{0}\} \rightarrow[0,1]$ dengan $\mu(x)=\frac{1}{\operatorname{ord}(x)}$ untuk setiap $x \in \mathbb{Z}_{5}-$ $\{\overline{0}\}$ merupakan subhimpunan fuzzy atas grup $\mathbb{Z}_{5}-\{\overline{0}\}$. Selanjutnya akan diselidiki apakah $\mu$ merupakan subgrup fuzzy atas grup $\mathbb{Z}_{5}-\{\overline{0}\}$.

Tabel 1. Hasil operasi subhimpunan fuzzy $\mu$

\begin{tabular}{|c|c|c|c|c|c|c|}
\hline $\boldsymbol{x}$ & $\boldsymbol{y}$ & $\boldsymbol{x} \times_{\mathbf{5}} \boldsymbol{y}$ & $\boldsymbol{\mu}\left(\boldsymbol{x} \times_{\mathbf{5}} \boldsymbol{y}\right)$ & $\boldsymbol{\mu}(\boldsymbol{x})$ & $\boldsymbol{\mu}(\boldsymbol{y})$ & $\boldsymbol{m i n}\{\boldsymbol{\mu}(\boldsymbol{x}), \boldsymbol{\mu}(\boldsymbol{y})\}$ \\
\hline$\overline{1}$ & $\overline{1}$ & $\overline{1}$ & 1 & 1 & 1 & $\frac{1}{4}$ \\
\hline$\overline{1}$ & $\overline{2}$ & $\overline{2}$ & $\frac{1}{4}$ & 1 & $\frac{1}{4}$ & $\frac{1}{4}$ \\
\hline$\overline{1}$ & $\overline{3}$ & $\overline{3}$ & $\frac{1}{4}$ & 1 & $\frac{1}{4}$ & $\frac{1}{2}$ \\
\hline$\overline{1}$ & $\overline{4}$ & $\overline{4}$ & $\frac{1}{2}$ & 1 & $\frac{1}{2}$ & $\frac{1}{4}$ \\
\hline$\overline{2}$ & $\overline{1}$ & $\overline{2}$ & $\frac{1}{4}$ & $\frac{1}{4}$ & 1 & $\frac{1}{4}$ \\
\hline$\overline{2}$ & $\overline{2}$ & $\overline{4}$ & $\frac{1}{4}$ & $\frac{1}{4}$ & $\frac{1}{4}$ & $\frac{1}{4}$ \\
\hline$\overline{2}$ & $\overline{3}$ & $\overline{1}$ & 1 & $\frac{1}{4}$ & $\frac{1}{4}$ & $\frac{1}{4}$ \\
\hline$\overline{2}$ & $\overline{4}$ & $\overline{3}$ & $\frac{1}{4}$ & $\frac{1}{4}$ & $\frac{1}{2}$ & $\frac{1}{4}$ \\
\hline$\overline{3}$ & $\overline{1}$ & $\overline{3}$ & $\frac{1}{4}$ & $\frac{1}{4}$ & $\frac{1}{4}$ \\
\hline$\overline{3}$ & $\overline{2}$ & $\overline{1}$ & 1 & $\frac{1}{4}$ & $\frac{1}{4}$ & $\frac{1}{4}$ \\
\hline
\end{tabular}




\begin{tabular}{|c|c|c|c|c|c|c|}
\hline$\overline{3}$ & $\overline{3}$ & $\overline{4}$ & $\frac{1}{2}$ & $\frac{1}{4}$ & $\frac{1}{4}$ & $\frac{1}{4}$ \\
\hline$\overline{3}$ & $\overline{4}$ & $\overline{2}$ & $\frac{1}{4}$ & $\frac{1}{4}$ & $\frac{1}{2}$ & $\frac{1}{4}$ \\
\hline$\overline{4}$ & $\overline{1}$ & $\overline{4}$ & $\frac{1}{2}$ & $\frac{1}{2}$ & 1 & $\frac{1}{2}$ \\
\hline$\overline{4}$ & $\overline{2}$ & $\overline{3}$ & $\frac{1}{4}$ & $\frac{1}{2}$ & $\frac{1}{4}$ & $\frac{1}{4}$ \\
\hline$\overline{4}$ & $\overline{3}$ & $\overline{2}$ & $\frac{1}{4}$ & $\frac{1}{2}$ & $\frac{1}{4}$ & $\frac{1}{4}$ \\
\hline$\overline{4}$ & $\overline{4}$ & $\overline{1}$ & 1 & $\frac{1}{2}$ & $\frac{1}{2}$ & $\frac{1}{2}$ \\
\hline
\end{tabular}

Tabel 2. Hasil dari invers subhimpunan fuzzy $\mu$

\begin{tabular}{|c|c|c|c|}
\hline $\boldsymbol{x}$ & $\boldsymbol{x}^{\mathbf{- 1}}$ & $\boldsymbol{\mu}(\boldsymbol{x})$ & $\boldsymbol{\mu}\left(\boldsymbol{x}^{\mathbf{- 1}}\right)$ \\
\hline$\overline{1}$ & $\overline{1}$ & 1 & 1 \\
\hline$\overline{2}$ & $\overline{3}$ & $\frac{1}{4}$ & $\frac{1}{4}$ \\
\hline$\overline{3}$ & $\overline{2}$ & $\frac{1}{4}$ & $\frac{1}{4}$ \\
\hline$\overline{4}$ & $\overline{4}$ & $\frac{1}{2}$ & $\frac{1}{2}$ \\
\hline
\end{tabular}

Berdasarkan hasil Tabel 1 diperoleh bahwa $\mu\left(x x_{5} y\right) \geq \min \{\mu(x), \mu(y)\}$ untuk setiap $x, y \in G$ dan dari hasil Tabel 2 diperoleh $\mu\left(x^{-1}\right) \geq \mu(x)$ untuk setiap $x \in G$. Dengan $\mu$ merupakan suatu subgrup fuzzy atas grup $\mathbb{Z}_{5}-\{\overline{0}\}$.

\section{Contoh 4}

Diketahui $H=\{1,-1, i,-i\}$ yang dilengkapi operasi $\times$ merupakan suatu grup dan fungsi $\sigma$ dengan definisi

$$
\sigma(x)=\left\{\begin{array}{l}
\cos \left(\frac{\operatorname{Arg}(x)}{2}\right), \text { untuk } x=1, i,-i \\
\sin \left(\frac{\operatorname{Arg}((x)}{3}\right), \text { untuk } x=-1
\end{array}\right.
$$


adalah suatu subhimpunan fuzzy. Selanjutnya akan ditunjukkan bahwa $\sigma$ merupakan subgrup fuzzy atas grup $H$.

Tabel 3. Hasil operasi subhimpunan fuzzy $\sigma$

\begin{tabular}{|c|c|c|c|c|c|c|}
\hline$x$ & $y$ & $x \times y$ & $\sigma(x \times y)$ & $\sigma(x)$ & $\sigma(y)$ & $\min \{\sigma(x), \sigma(y)\}$ \\
\hline 1 & 1 & 1 & 1 & 1 & 1 & 1 \\
\hline 1 & -1 & -1 & $\frac{\sqrt{3}}{2}$ & 1 & $\frac{\sqrt{3}}{2}$ & $\frac{\sqrt{3}}{2}$ \\
\hline 1 & $i$ & $i$ & $\frac{\sqrt{2}}{2}$ & 1 & $\frac{\sqrt{2}}{2}$ & $\frac{\sqrt{2}}{2}$ \\
\hline 1 & $-i$ & $-i$ & $\frac{\sqrt{2}}{2}$ & 1 & $\frac{\sqrt{2}}{2}$ & $\frac{\sqrt{2}}{2}$ \\
\hline-1 & 1 & -1 & $\frac{\sqrt{3}}{2}$ & $\frac{\sqrt{3}}{2}$ & 1 & $\frac{\sqrt{3}}{2}$ \\
\hline-1 & -1 & 1 & 1 & $\frac{\sqrt{3}}{2}$ & $\frac{\sqrt{3}}{2}$ & $\frac{\sqrt{3}}{2}$ \\
\hline-1 & $i$ & $-i$ & $\frac{\sqrt{2}}{2}$ & $\frac{\sqrt{3}}{2}$ & $\frac{\sqrt{2}}{2}$ & $\frac{\sqrt{2}}{2}$ \\
\hline-1 & $-i$ & $i$ & $\frac{\sqrt{2}}{2}$ & $\frac{\sqrt{3}}{2}$ & $\frac{\sqrt{2}}{2}$ & $\frac{\sqrt{2}}{2}$ \\
\hline$i$ & 1 & $i$ & $\frac{\sqrt{2}}{2}$ & $\frac{\sqrt{2}}{2}$ & 1 & $\frac{\sqrt{2}}{2}$ \\
\hline$i$ & -1 & $-i$ & $\frac{\sqrt{2}}{2}$ & $\frac{\sqrt{2}}{2}$ & $\frac{\sqrt{3}}{2}$ & $\frac{\sqrt{2}}{2}$ \\
\hline$i$ & $i$ & -1 & $\frac{\sqrt{3}}{2}$ & $\frac{\sqrt{2}}{2}$ & $\frac{\sqrt{2}}{2}$ & $\frac{\sqrt{2}}{2}$ \\
\hline$i$ & $-i$ & 1 & 1 & $\frac{\sqrt{2}}{2}$ & $\frac{\sqrt{2}}{2}$ & $\frac{\sqrt{2}}{2}$ \\
\hline \multirow[t]{2}{*}{40} & & & $\sqrt{2}$ & $\sqrt{2}$ & \multicolumn{2}{|r|}{ 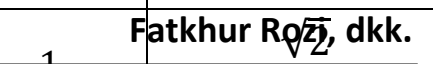 } \\
\hline & & & 2 & 2 & & 2 \\
\hline$-i$ & -1 & $i$ & $\frac{\sqrt{2}}{2}$ & $\frac{\sqrt{2}}{2}$ & $\frac{\sqrt{3}}{2}$ & $\frac{\sqrt{2}}{2}$ \\
\hline
\end{tabular}




\begin{tabular}{|c|c|c|c|c|c|c|}
\hline$-i$ & $i$ & 1 & 1 & $\frac{\sqrt{2}}{2}$ & $\frac{\sqrt{2}}{2}$ & $\frac{\sqrt{2}}{2}$ \\
\hline$-i$ & $-i$ & -1 & $\frac{\sqrt{3}}{2}$ & $\frac{\sqrt{2}}{2}$ & $\frac{\sqrt{2}}{2}$ & $\frac{\sqrt{2}}{2}$ \\
\hline
\end{tabular}

Tabel 4. Hasil dari invers subhimpunan fuzzy $\sigma$

\begin{tabular}{|c|c|c|c|}
\hline $\boldsymbol{x}$ & $\boldsymbol{x}^{\mathbf{- 1}}$ & $\boldsymbol{\sigma}(\boldsymbol{x})$ & $\boldsymbol{\sigma}\left(\boldsymbol{x}^{\mathbf{- 1}}\right)$ \\
\hline 1 & 1 & 1 & 1 \\
\hline-1 & -1 & $\frac{\sqrt{3}}{2}$ & $\frac{\sqrt{3}}{2}$ \\
\hline$-i$ & $-i$ & $\frac{\sqrt{2}}{2}$ & $\frac{\sqrt{2}}{2}$ \\
\hline & $i$ & $\frac{\sqrt{2}}{2}$ & $\frac{\sqrt{2}}{2}$ \\
\hline
\end{tabular}

Berdasarkan hasil Tabel 3 diperoleh bahwa $\sigma(x \times y) \geq \min \{\sigma(x), \sigma(y)\}$ untuk setiap $x, y \in G$ dan dari hasil Tabel 4 diperoleh $\sigma\left(x^{-1}\right) \geq \sigma(x)$ untuk setiap $x \in G$. Dengan demikian $\sigma$ merupakan suatu subgrup fuzzy atas grup $H$.

\subsection{Sifat Terkait Subgrup Fuzzy}

Pada bagian ini dijelaskan mengenai beberapa sifat terkait subgrup fuzzy, khususnya sifat yang terkait dengan syarat cukup dan perlu dari suatu subhimpunan fuzzy merupakan subgrup fuzzy. Sebelumnya terlebih dahulu disajikan Lemma berikut yang menjelaskan tentang nilai keanggotaan elemen identitas pada subgrup fuzzy atas suatu grup.

\section{Lemma 1}


Misalkan $\mu \in F(G)$ dan e adalah elemen identitas pada grup $G$, maka untuk setiap $x \in G$ berlaku

1. $\mu(e) \geq \mu(x)$

2. $\mu(x)=\mu\left(x^{-1}\right)$

\section{Bukti.}

1. Perhatikan bahwa $G$ adalah suatu grup, jadi untuk setiap $x \in G$ selalu terdapat $x^{-1} \in G$ sedemikian sehingga $x x^{-1}=e$. Dari sini diperoleh bahwa

$$
\mu(e)=\mu\left(x x^{-1}\right) \geq \min \left\{\mu(x), \mu\left(x^{-1}\right)\right\} \geq \min \{\mu(x), \mu(x)\}=\mu(x) .
$$

Jadi untuk setiap $x \in G$ berlaku $\mu(e) \geq \mu(x)$

2. Perhatikan bahwa untuk setiap $x \in G$ dapat dinyatakan sebagai $\left(x^{-1}\right)^{-1}$. Dari sini diperoleh

$$
\mu(x)=\mu\left(\left(x^{-1}\right)^{-1}\right) \geq \mu\left(x^{-1}\right) .
$$

Selanjutnya, karena $\mu$ adalah suatu subgrup fuzzy atas grup G maka untuk setiap $x \in G$ berlaku $\mu\left(x^{-1}\right) \geq \mu(x)$. Lebih lanjut karena $\mu(x) \geq \mu\left(x^{-1}\right)$ dan $\mu\left(x^{-1}\right) \geq \mu(x)$ maka haruslah $\mu(x)=\mu\left(x^{-1}\right)$.

Pada Contoh 3 dijelaskan bahwa $\mu$ merupakan suatu subgrup fuzzy atas grup $\mathbb{Z}_{5}-\{\overline{0}\}$ dengan elemen identitas $e=\overline{1}$. Dari Tabel 1 terlihat $\mu(\overline{1}) \geq \mu(x)$ untuk setiap $x \in \mathbb{Z}_{5}-\{\overline{0}\}$, dan pada Tabel 2 terlihat bahwa $\mu(x)=\mu\left(x^{-1}\right)$ untuk setiap $x \in \mathbb{Z}_{5}-\{\overline{0}\}$. Sementara itu, pada Contoh 4 dijelaskan bahwa $\sigma$ merupakan suatu subgrup fuzzy atas grup $H$ dengan $e=1$. Dari Tabel 3 dapat diketahui bahwa $\sigma(1) \geq$ $\sigma(x)$ untuk setiap $x \in H$, dan pada Tabel 4 dapat terlihat bahwa $\mu(x)=\mu\left(x^{-1}\right)$ untuk setiap $x \in H$.

Teorema-teorema berikut ini menjelaskan tentang syarat cukup dan perlu untuk suatu subhimpunan fuzzy atas suatu grup menjadi subgrup fuzzy atas suatu grup.

Fatkhur Rozi, dkk.

\section{Teorema 1.}


$\mu \in F P(G)$ merupakan subgrup fuzzy atas grup $G$ jika dan hanya jika untuk setiap $x, y \in G, \mu\left(x y^{-1}\right) \geq \min \{\mu(x), \mu(y)\}$

\section{Bukti.}

$(\Rightarrow)$ Diketahui $\mu \in F P(G)$ merupakan subgrup fuzzy atas grup $G$, maka untuk setiap $x, y \in G$ berlaku $\mu\left(x y^{-1}\right) \geq \min \left\{\mu(x), \mu\left(y^{-1}\right)\right\}$. Karena untuk setiap $y \in G$ berlaku $\mu(y)=\mu\left(y^{-1}\right)$ maka akibatnya $\mu\left(x y^{-1}\right) \geq \min \{\mu(x), \mu(y)\}$.

$(\Leftarrow)$ Diketahui bahwa untuk setiap $x, y \in G, \quad \mu\left(x y^{-1}\right) \geq \min \{\mu(x), \mu(y)\}$, maka diperoleh

$$
\mu(e)=\mu\left(x x^{-1}\right) \geq \min \{\mu(x), \mu(x)\}=\mu(x), \text { untuk setiap } x \in G .
$$

Hal ini mengakibatkan $\mu(x)=\mu(e x) \geq \min \left\{\mu(e), \mu\left(x^{-1}\right)\right\}=\mu\left(x^{-1}\right)$, dengan kata lain berlaku $\mu(x) \geq \mu\left(x^{-1}\right)$. Sementara itu $\left(x^{-1}\right)=\mu\left(e x^{-1}\right) \geq \min \{\mu(e), \mu(x)\}=$ $\mu(x)$, yang berarti bahwa $\mu\left(x^{-1}\right) \geq \mu(x)$. Jadi terbukti bahwa $\mu\left(x^{-1}\right)=\mu(x)$, untuk setiap $x \in G$.

Selanjutnya, $\mu(x y) \geq \min \left\{\mu(x), \mu\left(y^{-1}\right)\right\} \geq \min \{\mu(x), \mu(y)\}$ untuk setiap $x, y \in G$. Dengan demikian syarat 1 dan 2 untuk subgrup fuzzy terpenuhi. Jadi terbukti bahwa $\mu$ merupakan subgrup fuzzy atas grup $G$.

Pada Contoh 3 dijelaskan bahwa apabila $\mu$ merupakan suatu subgrup fuzzy atas grup $\mathbb{Z}_{5}-\{\overline{0}\}$ maka berlaku $\mu\left(x y^{-1}\right) \geq \min \{\mu(x), \mu(y)\}$ untuk setiap $x, y \in$ $\mathbb{Z}_{5}-\{\overline{0}\}$. Sebaliknya apabila diketahui $\mu\left(x y^{-1}\right) \geq \min \{\mu(x), \mu(y)\}$ untuk setiap $x, y \in \mathbb{Z}_{5}-\{\overline{0}\}$ maka terlihat bahwa $\mu$ merupakan suatu subgrup fuzzy atas grup $\mathbb{Z}_{5}-\{\overline{0}\}$. Demikian juga berlaku untuk Contoh 4 .

\section{Teorema 2}

$\mu \in F P(G)$ merupakan subgrup fuzzy atas grup $G$ jika dan hanya jika $\mu$ memenuhi

1. $\mu \circ \mu \subseteq \mu$

2. $\mu^{-1}=\mu$.

\section{Bukti.}


$\Leftrightarrow$ Diketahui $\mu$ merupakan subgrup fuzzy atas $G$. Akan ditunjukkan $\mu \circ \mu \subseteq \mu$ dan $\mu^{-1}=\mu$, yakni untuk setiap $x \in G$ berlaku $(\mu \circ \mu)(x) \leq \mu(x)$ dan $\mu^{-1}(x)=\mu(x)$. Perhatikan bahwa

$$
(\mu \circ \mu)(x)=\sup \{\min \{\mu(y), \mu(z)\} \mid y z=x\}
$$

dan karena $\mu$ adalah subgrup fuzzy dari $G$ maka $\mu(y z) \geq \min \{\mu(y), \mu(z)\}$ untuk setiap $y, z \in G$.

Dengan demikian $(\mu \circ \mu)(x) \leq \mu(x)$ untuk setiap $x \in G$ dan berarti $\mu \circ \mu \subseteq \mu$.

Sementara itu, $\mu^{-1}(x)=\mu\left(x^{-1}\right)=\mu(x)$ untuk setiap $x \in G$. Dengan demikian terbukti bahwa $\mu^{-1}=\mu$.

$(\Leftarrow)$ Diketahui adalah $\mu$ memenuhi $\mu \circ \mu \subseteq \mu$ dan $\mu^{-1}=\mu$. Akan ditunjukkan bahwa $\mu$ merupakan subgrup fuzzy atas grup $G$. Perhatikan bahwa diketahui $\mu \circ \mu \subseteq \mu$, sehingga untuk setiap $x, y \in G$ berlaku $\mu\left(x y^{-1}\right) \geq(\mu \circ \mu)\left(x y^{-1}\right)=$ $\min \left\{\mu(x), \mu\left(y^{-1}\right)=\min \left\{\mu(x), \mu^{-1}(y)\right\}\right\}$. Sementara itu, karena $\mu^{-1}=\mu$ maka $\mu^{-1}(y)=\mu(y)$, sehingga $\mu\left(x y^{-1}\right) \geq \min \{\mu(x), \mu(y)\}$. Jadi $\mu$ memenuhi syarat 1 dan 2 subgrup fuzzy atas grup $G$. Dapat disimpulkan bahwa $\mu$ merupakan subgrup fuzzy atas grup $G$.

\section{KESIMPULAN DAN SARAN}

Subgrup fuzzy atas suatu grup $G$ dapat dibentuk melalui subhimpunan fuzzy atas grup $G$. Syarat cukup dan perlu dari suatu subhimpunan fuzzy merupakan subgrup fuzzy adalah nilai keanggotaan dari hasil kali dari sembarang elemen dan sembarang invers elemen pada grup $G$ selalu lebih dari atau sama dengan minimum dari nilai keanggotaan kedua elemen $G$ tersebut. Selain itu, syarat cukup dan perlu lainnya adalah hasil kali sembarang subhimpunan fuzzy selalu termuat dalam subłhimpunan fuzzy tersebut, dan invers dari sembarang subhimp himpunan fuzzy itu sendiri.

Penelitian lebih lanjut dapat dilakukan pada pembentukan subgrup fuzzy normal dan sifat-sifat yang terkait. 


\section{DAFTAR PUSTAKA}

Fraleigh, J.B., 2002. A First Course in Abstract Algebra, $7^{\text {rd }}$ Edition. New York: Addison-Wesley Publising Company.

Judson, T.W., 2011. Abstract Algebra Theory and Application. Amerika Serikat: Virginia Commonwealth University Mathematics.

Mordeson, J.N dan Malik, D.S. 2002. Fuzzy Automata and Languages Theory and Applications. Amerika Serikat: Chapman \& Hall/CRC.

Mordeson, J.N, Bhutani, K.R, dan Rosenfeld, A., 2005. Fuzzy Groups Theory. New York: Springer Berlin Heidelberg.

Lee, K.H. 2005. First Course on Fuzzy Theory and Applications. Spinger-Verlag Berlin Heidelberg.

Mufidah, A.S., 2011. Ruang Vektor Fuzzy dari Matriks Fuzzy $m \times n$. Skripsi. Malang: Jurusan Matematika, Universitas Islam Negeri Malik Ibrahim. 